\title{
Efeito dos Tratamentos Térmicos de Normalização e de Solubilização na Microestrutura de uma Junta Dissimilar Soldada entre um Tubo de Aço API 5 L X-52 e o Inconel 625
}

\author{
Jefferson Pinto Soares ${ }^{1}$, Luis Augusto Hernandez Terrones², Ronaldo Paranhos² \\ 1 Petróleo Brasileiro S.A. - PETROBRAS, Unidade de Operações de Exploração e Produção na Bacia de Campos - UO/BC, \\ Macaé, RJ, Brasil. \\ 2 Universidade Estadual do Norte Fluminense Darcy Ribeiro - UENF, Centro de Ciência e Tecnologia - CCT, Laboratório de \\ Materiais Avançados - LAMAV, Campos dos Goytacazes, RJ, Brasil.
}

Recebido: 23 Out., 2017

Aceito: 23 Nov., 2017

E-mails: jeffersonpsoares@petrobras. com.br (JPS), lucho@uenf.br (LAHT), paranhos@uenf.br (RP)
Este é um artigo publicado em acesso aberto (Open Access) sob a licença Creative Commons Attribution Non-Commercial, que permite uso, distribuição e reprodução em qualquer meio, sem restriçōes desde que sem fins comerciais e que 0 trabalho original seja corretamente citado.
Resumo: O propósito deste trabalho é comparar as mudanças na microestrutura e na dureza de um tubo de aço API 5L X-52, revestido internamente por soldagem com Inconel 625, após a execução dos tratamentos térmicos de normalização a $1100{ }^{\circ} \mathrm{C}$ por 60 min. e resfriamento ao ar, e de solubilização a $1030^{\circ} \mathrm{C}$ com aquecimento por indução eletromagnética por $30 \mathrm{~s}$. e resfriamento em água. Foram utilizadas técnicas de microscopia ótica (MO) e eletrônica de varredura (MEV), análise por espectroscopia de energia dispersiva (EDS) e dureza Vickers. $\mathrm{Na}$ condição como soldada, o metal de base (MB) teve na zona termicamente afetada (ZTA) a formação de zona de grãos grosseiros (ZGG) com dureza média de 234 HV. A zona parcialmente diluída (ZPD) se apresentou clara, sem contornos de grãos, com alto teor de ferro e dureza média de $370 \mathrm{HV}$, indicando ser constituída de martensita. No revestimento, a microestrutura é austenítica dendrítica com formação de carbetos de $\mathrm{Nb}$ e indícios da presença da fase Laves, com dureza média de $287 \mathrm{HV}$ em suas camadas. Na condição após normalização, a ZTA foi suprimida e houve refino na microestrutura do MB; a ZPD foi mantida com sua morfologia original, porém com redução de cerca de 15\% em sua dureza; no revestimento, a microestrutura tornou-se granular, com indício da dissolução da fase Laves e redução de sua dureza de cerca de $26 \%$. Na condição após solubilização, a ZTA do MB foi eliminada, a ZPD manteve sua morfologia e microestrutura original, mas reduziu sua dureza em cerca de 30\%; no revestimento, a microestrutura e precipitados foram mantidos, mas houve uma redução da dureza em cerca de $20 \%$. Por fim, este trabalho conclui que ambos os tratamentos térmicos foram considerados benéficos às propriedades do tubo de aço API 5L X-52 revestido internamente com Inconel 625. Promoveram a homogeneização da microestrutura e a redução de dureza na ZTA do MB, significativa redução da dureza na ZPD e, nas camadas do revestimento, a redução e adequação da dureza às normas técnicas pertinentes, possibilitando assim a sua utilização em ambientes agressivos, principalmente na indústria offshore de petróleo e gás.

Palavras-chave: Revestimento; Inconel 625; Normalização; Solubilização.

\section{Effect of Normalizing and Solution Heat Treatments in the Microstructure of a Dissimilar Joint Welded Between an API 5L X-52 Steel Pipe and Inconel 625}

Abstract: The purpose of this work is to compare changes in the microstructure and hardness of an API 5LX-52 steel pipe, internally cladded by welding with Inconel 625, after the execution of two heat treatments: normalization at $1100{ }^{\circ} \mathrm{C}$ for $60 \mathrm{~min}$. and air cooled, and solubilization at $1030^{\circ} \mathrm{C}$ with heating by electromagnetic induction for $30 \mathrm{~s}$. and cooling in water. There were used techniques of optical microscopy (OM) and scanning electron microscopy (SEM), analysis by energy dispersive spectroscopy (EDS) and Vickers hardness. In the as-welded condition, the base metal (BM) had in its heat affected zone (HAZ) the formation of the coarse grain zone (CGZ) with average hardness of $234 \mathrm{HV}$. The partially diluted zone (PDZ) was presented clear, without grain boundaries, with high iron content and average hardness of $370 \mathrm{HV}$, indicating to be constituted by martensite. In the weld overlay, the microstructure is austenitic with dendritic cell shape with carbides of $\mathrm{Nb}$ and indications of precipitation of secondary Laves phases, with average hardness of $287 \mathrm{HV}$ on its layers. In the condition after normalization, HAZ was suppressed and there was observed refinement in the BM microstructure; PDZ was maintened with its original morphology, but hardness was reduced about $15 \%$; in the weld overlay, the microstructure became granular with indication of dissolution of the Laves phase 
and reduction of its hardness of $26 \%$ on average. In the condition after solubilization, HAZ of the BM was eliminated, PDZ maintened its morphology and previous microstructure, but its hardness reduced approximately $30 \%$; in the weld overlay, microstructure and precipitates were maintened, but there was a reduction of hardness by about $20 \%$. Finally, this work concludes that both heat treatments were considered beneficial to the properties of steel pipe API $5 \mathrm{~L}$ X-52 internally cladded by Inconel 625. They promoted homogeneization of microstructure and hardness reduction of both $\mathrm{BM}$ and $\mathrm{HAZ}$, significative reduction of PDZ hardness and, in the cladding layers, a reduction and adequation of hardness to the pertinent standards, allowing its use in aggressive enviromnents, mainly in the offshore and gas industry.

Key-words: Cladding; Inconel 625; Normalizing; Solution heat treatment.

\section{Introdução}

As tubulações de aço utilizadas na produção de óleo e gás em águas ultra profundas estão inseridas em ambiente hostil com a presença de altos índices de $\mathrm{H}_{2} \mathrm{~S}, \mathrm{CO}_{2}$ e sólidos em suspensão. Atualmente, o revestimento destes tubos utilizando ligas de níquel ganha espaço principalmente por seu caráter econômico, onde o material mais nobre é utilizado somente nas regiões de interesse.

A soldagem de revestimento é um processo no qual uma liga é depositada na superfície de um metal de base, ou para retorná-la às dimensões originais ou para obter alguma propriedade desejada, como resistência ao desgaste, ao impacto, à corrosão e fadiga [1]. Neste contexto, a soldagem de revestimento com superligas à base de níquel tem sido uma alternativa interessante, pois confere aos equipamentos uma alta resistência à corrosão com um custo inferior, se comparado à fabricação de componentes ou tubulações maciças com superligas [2].

A soldagem dissimilar de revestimento entre um aço C-Mn e uma liga metálica mais nobre, como as ligas de níquel, apresenta algumas limitações metalúrgicas devido à grande diferença de composição química entre ambos os materiais. A esta prática está associada a presença de zonas descontínuas próximas à linha de fusão, chamadas zonas parcialmente diluídas (ZPD), que são frágeis, duras e responsáveis pela fragilização e perda de tenacidade da junta [3].

As zonas parcialmente diluídas podem falhar quando submetidas a tensões decorrentes de sua utilização. Uma alternativa ao aumento de dureza na interface da solda é a realização de tratamento térmico pós-soldagem (TTPS). No entanto, alguns TTPS são longos, e a possibilidade de formação de fases frágeis é real nesta situação. Portanto, levando-se em consideração os requisitos impostos no setor de exploração de petróleo, deve ser avaliado o comportamento mecânico e microestrutural de amostras submetidas ao ciclo de tratamento térmico [4].

A normalização nos aços (metal base) tem por objetivo refinar e homogeneizar a estrutura do aço, conferindo-lhe melhores propriedades que as obtidas no recozimento. O resfriamento, após austenitização, é geralmente ao ar [5]. Já no Inconel 625, a normalização é usada para homogeneizar a sua estrutura fundida (normalização ou recozimento) e aliviar tensões, seja na fundição ou na soldagem [6].

O tratamento térmico de solubilização é mais frequentemente especificado para os aços inoxidáveis austeníticos. O principal objetivo deste tratamento, como o nome indica, tanto para os aços quanto para as superligas de níquel, é dissolver as fases precipitadas durante o processamento termomecânico do material [7].

Este trabalho tem por objetivo avaliar o efeito de tratamentos térmicos em tubos de aço API $5 \mathrm{~L} X-52$ revestidos com Inconel 625 pelo processo TIG hot wire automatizado. Foram estudadas e comparadas a condição como soldada, após normalização e após solubilização. Foi determinada a influência dos tratamentos térmicos na microestrutura e na dureza do metal base (MB), da ZPD e da camada do revestimento.

\section{Materiais e Métodos}

A Tabela 1 mostra a composição química típica do MB (tubo API 5 L Gr X-52 [8] com 12,7 mm de espessura e 219,1 mm de diâmetro externo) e do eletrodo consumível (ER NiCrMo-3 de 1,2 mm de diâmetro).

O tubo foi revestido pelo processo TIG automatizado com a variante hot wire na empresa PROTUBO CLADTEC. Os parâmetros de soldagem usados foram: corrente de soldagem na faixa de 170-262 A, tensão de soldagem na faixa de 11,4-12,8 V, polaridade direta, velocidade de avanço de $340 \mathrm{~mm} / \mathrm{min}$., na posição plana. A energia de soldagem variou de 440 a $480 \mathrm{~J} / \mathrm{mm}$. Foi realizado pré-aquecimento na peça a temperatura superior a $62^{\circ} \mathrm{C}$, porém a temperatura de interpasse foi inferior a $180^{\circ} \mathrm{C}$. Foram depositadas 4 camadas de solda, e o revestimento 
Efeito dos Tratamentos Térmicos de Normalização e de Solubilização na Microestrutura de uma Junta Dissimilar Soldada entre um Tubo de Aço API 5 L X-52 e o Inconel 625

Tabela 1. Composição química típica do tubo API 5L Gr X-52 [8] e do eletrodo ER NiCrMo-3.

\begin{tabular}{ccccccccc}
\hline & \multicolumn{7}{c}{ Elemento químico (\% peso) } \\
Tubo & $\mathrm{C}$ & $\mathrm{Mn}$ & $\mathrm{P}$ & $\mathrm{S}$ & $\mathrm{Si}$ & $\mathrm{Al}$ & $\mathrm{Nb}+\mathrm{Ti}+\mathrm{V}$ \\
& 0,206 & 1,27 & 0,020 & 0,013 & 0,294 & 0,03 & $\mathrm{~N}$ & \\
ER NiCrMo-3 & $\mathrm{C}$ & $\mathrm{Mn}$ & $\mathrm{Mo}$ & $\mathrm{Cr}$ & $\mathrm{Si}$ & $\mathrm{Ni}$ & $\mathrm{Nb}$ & $\mathrm{Fe}$ \\
& 0,04 & 0,60 & 9,0 & 22,0 & 0,50 & 61,6 & 3,30 & 3,0 \\
\hline
\end{tabular}

apresentou espessura de $7,7 \mathrm{~mm}$. A fim de minimizar a diluição, a corrente de soldagem foi mais baixa no primeiro cordão e mais elevada nos últimos passes.

Após a soldagem de revestimento, 3 seções foram retiradas, sendo uma mantida na condição como soldada. A segunda após o tratamento térmico de normalização, que foi realizado em forno, com patamar de 60 min a $1100{ }^{\circ} \mathrm{C}$ seguido de resfriamento ao ar e a terceira solubilizada. A solubilização foi feita por técnica de indução eletetromagnética à temperatura de $1030^{\circ} \mathrm{C}$ por 30 s., seguido de resfriamento em água. A Figura 1 mostra um pedaço do arco já seccionado, evidenciando o metal de base e o revestimento.

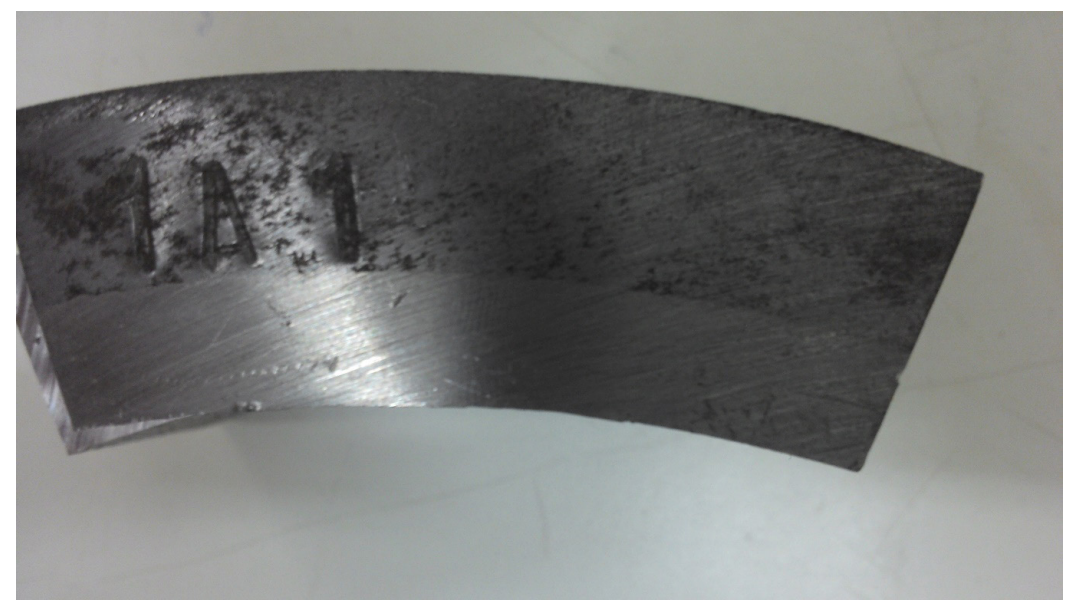

Figura 1. Pedaço do arco retirado da seção transversal do tubo na condição como soldado.

Para análise da microestrutura, cada uma das amostras foi seccionada e preparada metalograficamente seguindo as seguintes etapas: lixamento com lixas de 100 a até 1200 mesh; polimento com pasta de alumina de $1 \mu \mathrm{m}$ e 0,3 $\mu \mathrm{m}$. O ataque químico foi realizado em duas etapas e com soluções diferentes devido à presença de dois materiais dissimilares nas amostras analisadas. O ataque diferenciado visa obter melhor revelação em todas as regiões presentes. As soluções utilizadas foram: Nital 2\% (2\% de ácido nítrico, diluído em etanol) para ataque químico do metal base e da ZTA. Ácido oxálico $10 \%$ (10\% de $\mathrm{H}_{2} \mathrm{C}_{2} \mathrm{O}_{4}$ diluído em água destilada) para ataque eletrolítico da ZPD e camadas do revestimento. Foram utilizados como parâmetros do ataque eletrolítico: tensão de $2 \mathrm{~V}$, corrente de 0,18 A e tempo de $10 \mathrm{~s}$.

Para análise da microestrutura foi utilizado: microscopia ótica, com Neophot 32 e Olympus GX41 e microscopia confocal com equipamento Confocal Olympus 3D Measuring Laser Microscope OLS4000. Também foi utilizado um microscopio eletrônico de varredura (MEV) marca Shimadzu SSX-550 acoplado com EDS (Energy Disperse x-ray Spectroscopy). Foram observadas regiões do MB, da interface (particularmente a ZPD) e do revestimento, com diversos aumentos, para a identificação das fases presentes.

Medições de dureza Vickers foram realizados no MB e sua ZTA, na interface e no revestimento das 3 condições estudadas (como soldado, normalizado e solubilizado) com o objetivo de avaliar as alterações de dureza nas diversas regiões da junta e a influência dos tratamentos térmicos realizados. Foram feitas sete impressões em cada região: MB e sua ZTA, contemplando a zona de grãos grosseiros (ZGG) e a zona de grãos finos (ZGF), na ZPD e nas camadas de revestimento. Na ZPD a carga utilizada foi de $10 \mathrm{~g}$ devido à sua pequena extensão. No MB, na ZTA e no revestimento foi utilizada carga de $300 \mathrm{~g}$. 


\section{Resultados e Discussão}

Condição como Soldado: a seção transversal do tubo de aço API $5 \mathrm{~L}$ X-52 revestido internamente com Inconel 625 pelo processo TIG automatizado hot wire na condição como soldado apresenta as seguintes regiões: o MB e sua ZTA, a ZPD e as camadas de revestimento. A Figura 2 mostra a microestrutura do MB, na condição como recebido, constituída de grãos de ferrita (regiões claras) e grãos de perlita (região escura) em menor quantidade. Esta microestrutura é típica do aço API 5L X-52.

A Figura 3 mostra a microestrutura da ZTA. A ZGG da ZTA é composta predominante de ferrita com segunda fase alinhada. Já a ZGF da ZTA apresenta ferrita poligonal de pequeno tamanho de grão.

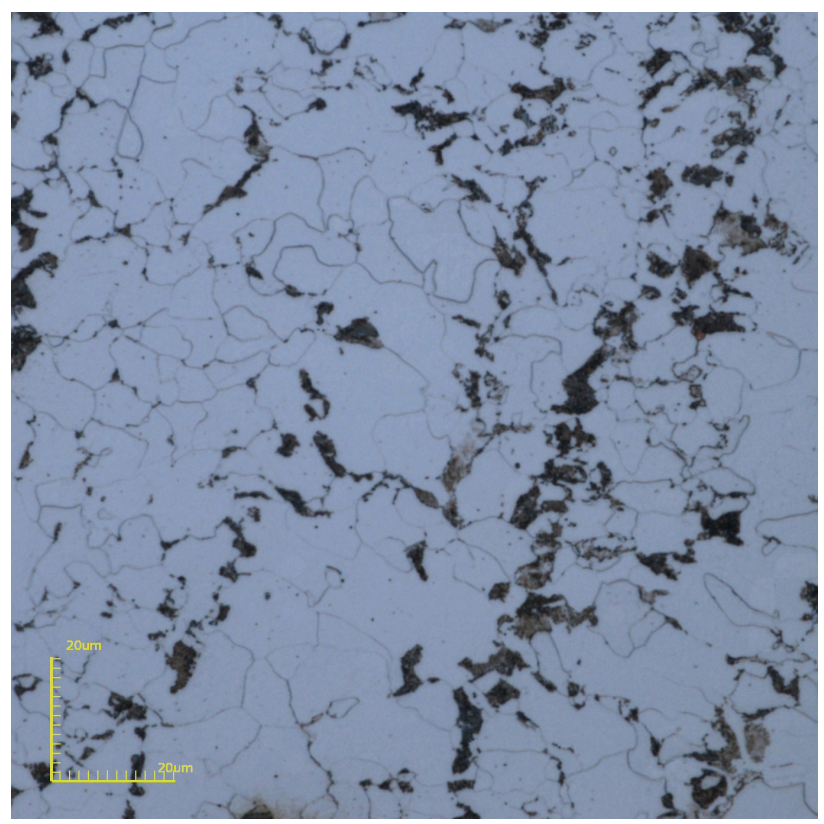

Figura 2. MB, na condição como recebido. Microscopia Confocal. Reagente: Nital 2\%.

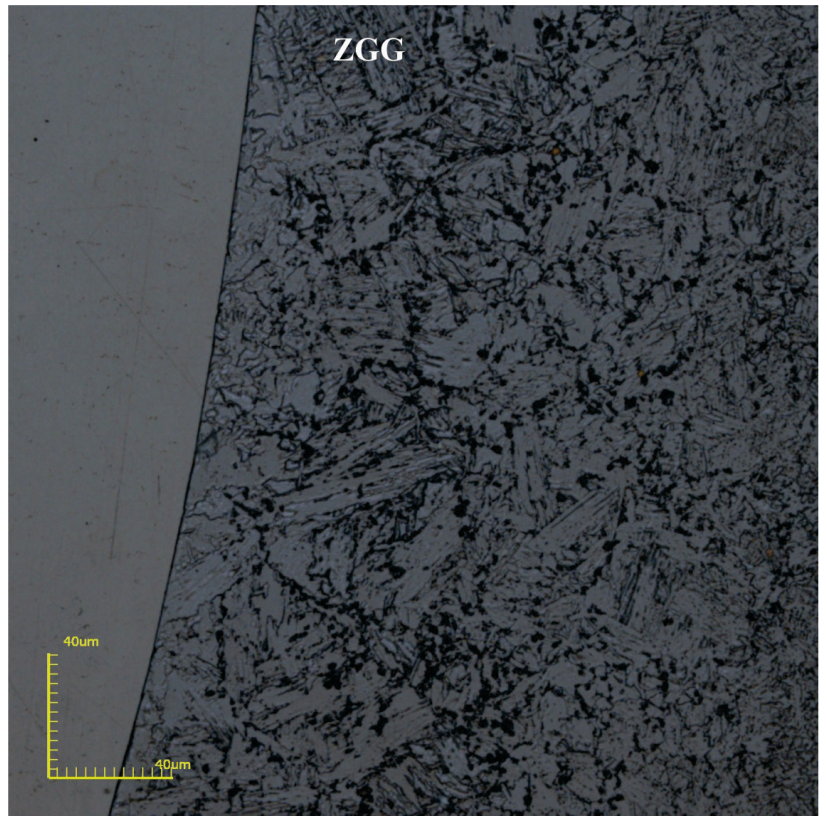

Figura 3. ZTA na condição como soldado. Revestimento à esquerda; ZGG indicada. Microscopia Confocal. Reagente: Nital $2 \%$. 
Efeito dos Tratamentos Térmicos de Normalização e de Solubilização na Microestrutura de uma Junta Dissimilar Soldada entre um Tubo de Aço API 5L X-52 e o Inconel 625

A Tabela 2 mostra os resultados de dureza obtidos. Os valores médios de dureza foram de $154 \mathrm{HV}$ no MB, 234 HV na ZGG e de 188 HV na ZGF. Todos os resultados de dureza estão abaixo de 300 HV, e, complementados com as micrografias apresentadas nas Figuras 2 e 3 , indicam a não formação de constituíntes frágeis na ZTA. Valores de dureza nos aços carbono acima de 300 HV são indícios da formação de constituíntes frágeis como martensita, bainita e constituintes A-M [9].

Tabela 2. Valores de dureza mínimo, máximo e média do MB, ZGF e ZGG na condição como soldado (carga de 300 g).

\begin{tabular}{cccc}
\hline & MB & ZGF & ZGG \\
Máx. & 160 & 208 & 238 \\
Mín. & 148 & 172 & 232 \\
Média & 154 & 188 & 234 \\
\hline
\end{tabular}

A Figura 4 mostra, da direita para a esquerda, o MB, a região de interface (ZPD), a primeira e a segunda camada do revestimento. Situada entre o MB e o revestimento, encontra-se a ZPD, que pode ser facilmente observada por microscopia ótica. Esta se apresenta como a região mais clara entre o revestimento, à esquerda, e o MB, à direita.

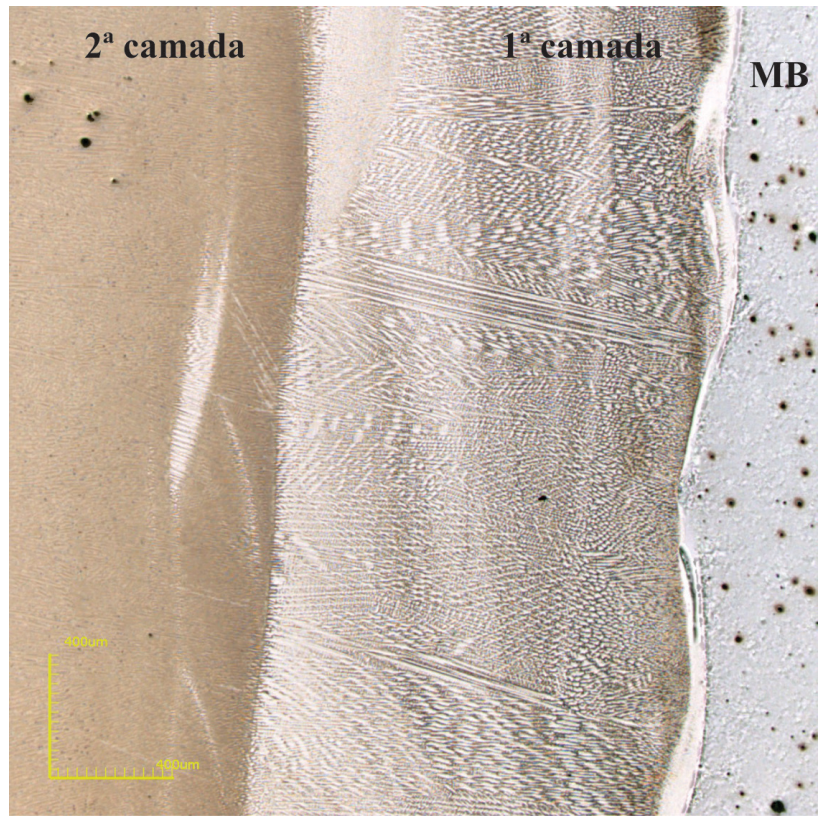

Figura 4. MB, ZPD, 1a e 2a camadas de revestimento, da direita para a esquerda. Microscopia Confocal.

A Figura 5 mostra que a ZPD apresenta estrutura na forma de ilhas e baias. Quando o MB líquido é impulsionado para dentro da poça de fusão, através da convecção que age nesta poça, ocorre a formação da ZPD. A convecção gerada pelo arco elétrico é capaz de empurrar o metal de adição líquido para dentro da camada do MB líquido gerando inclusões e, consequentemente, formando regiões de orientações aleatórias. Este movimento hidrodinâmico explica a ampla variação na espessura das ZPD's [10].

A ZPD foi dividida em duas regiões distintas para sua caracterização química por EDS: a região 1, mais próxima à linha de fusão com o MB; e a região 2, mais afastada da linha de fusão com o aço. Os resultados do EDS nessas regiões são mostrados na Figura 6. A região 1, Figura 6a, apresentou picos de maior intensidade de Fe e com menor intensidade de $\mathrm{Ni}$ e $\mathrm{Cr}$. Esta composição, rica em ferro, pode levar à desestabilização da austenita e ao aumento da temperabilidade do material, favorecendo a formação da microestrutura martensítica. Silva et al. [10] relatam que os aspectos composicionais desta zona são complexos e resultam da incorporação de quantidades muito pequenas de elementos de liga, que não é suficiente para estabilizar a estrutura austenítica, mas suficiente para elevar a temperabilidade do material, favorecendo a formação da martensita. 


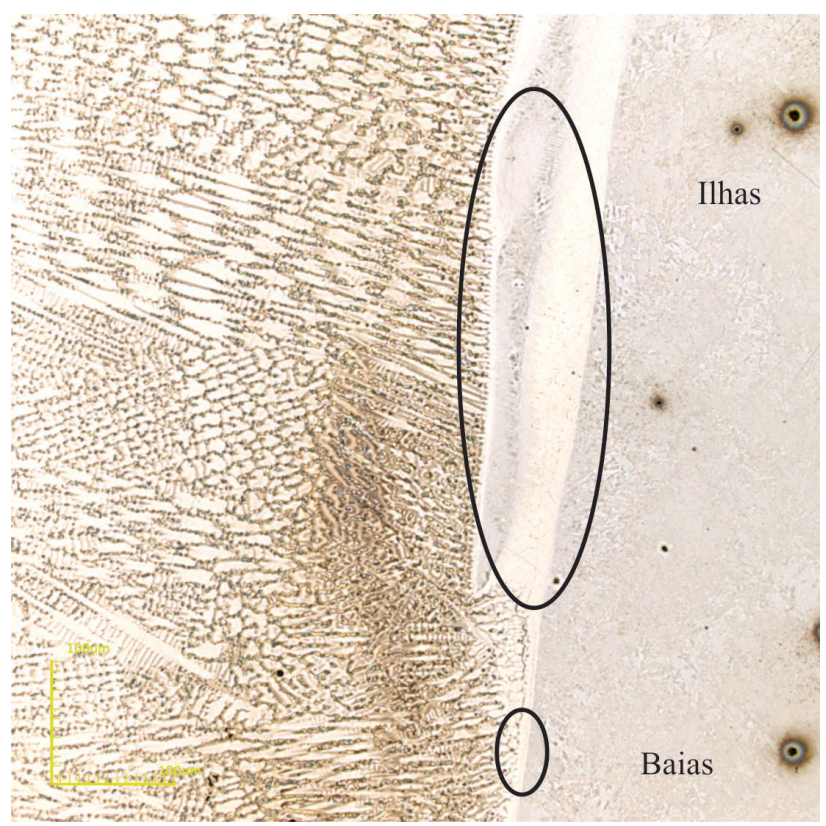

Figura 5. Estruturas de ilhas e baias na ZPD. Microscopia Confocal.

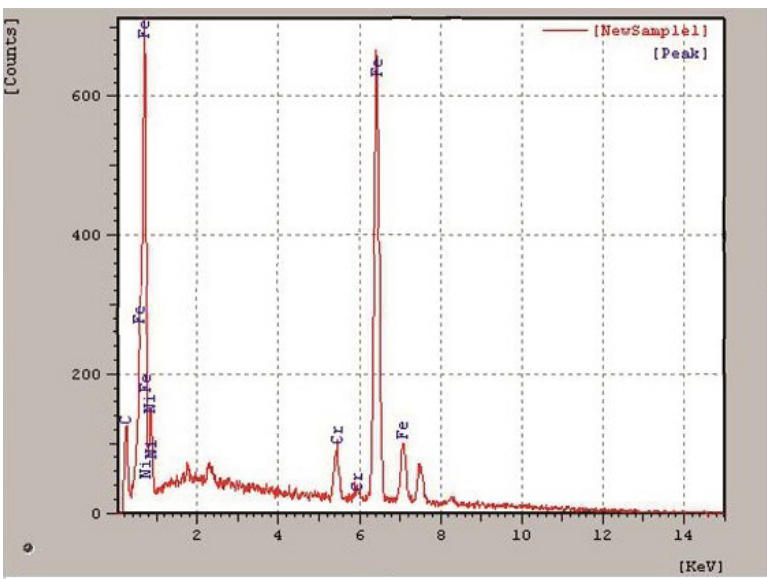

(a)

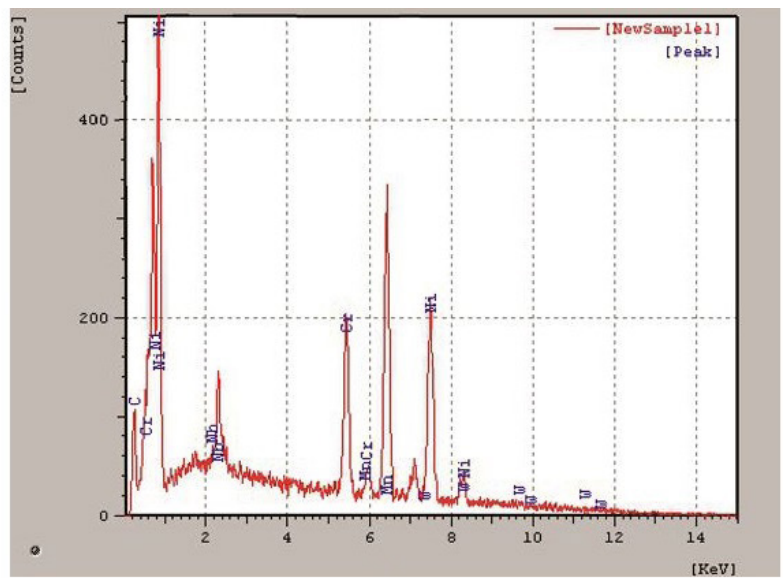

(b)

Figura 6. Analise por EDS dos elementos químicos presentes na ZPD. Região 1, mais próximo à linha de fusão (a); e região 2, mais afastado da linha de fusão (b).

A Figura 6b apresenta o resultado da análise por EDS da região 2, mais afastada do $\mathrm{MB}$, que apresenta picos mais pronunciados de $\mathrm{Cr}$ e $\mathrm{Ni}$ e picos menores de $\mathrm{Mo} \mathrm{e} \mathrm{Nb}$. A presença destes elementos químicos é compatível com a composição química do eletrodo ER NiCrMo-3, apresentada na Tabela 1.

Foram realizadas 10 impressões para o ensaio de dureza Vickers na região da ZPD com carga de 10 g. A ZPD apresentou média de dureza de 428 HV, com valor mínimo de 303 HV e máximo de 505 HV. O valor médio de dureza encontrado está na faixa de dureza da estrutura martensítica [11].

A Figura 7 mostra a microestrutura da primeira camada de Inconel 625. A fase predominante é a austenita com formato dendrítico, característica do Inconel 625 em sua estrutura bruta de fusão, típico da soldagem. Pode-se observar a presença de estrutura dendrítica-colunar e dendrítica-celular. As dendritas apresentam-se com cor mais clara enquanto que as regiões interdendríticas aparecem mais escurecidas. Importante observar que as 4 camadas do revestimento apresentaram estrutura similar à da Figura 7. 


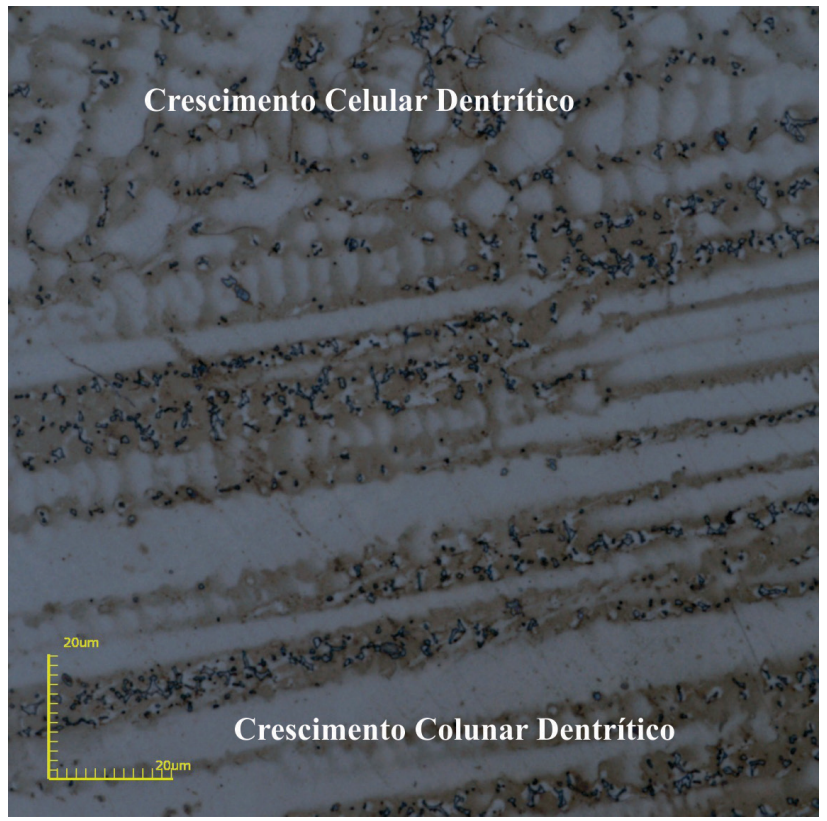

Figura 7. Micrografia da primeira camada de revestimento. Microscopia Confocal.

A Figura 8 mostra a microestrutura da segunda camada do revestimento sob um aumento de 3500x. Observa-se com maiores detalhes nesta imagem a morfologia irregular dos precipitados formados após a solidificação do Inconel 625. A composição química nos 3 pontos indicados foi verificada por análise no EDS. Os pontos 1 e 2 estão sob precipitados, enquanto o ponto 3 está localizado na matriz inconel do revestimento.

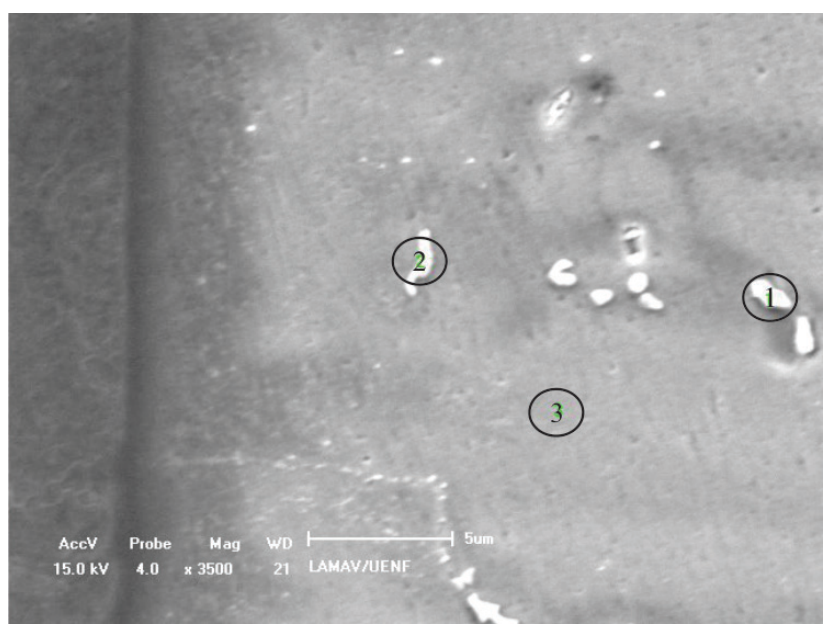

Figura 8. Micrografia (MEV), com aumento de 3500X. Os pontos 1 e 2 indicam dois precipitados e o 3 a matriz de Inconel 625 , onde foram feitas as análises por EDS.

A Figura 9a mostra o EDS obtido no ponto 1 (precipitado) indicado na Figura 8, o qual foi muito semelhante ao obtido no ponto 2. Os seguintes elementos químicos, em ordem decrescente de intensidade dos picos, foram identificados: $\mathrm{Nb}, \mathrm{Ni}, \mathrm{Cr}$, Fe e Si. A grande concentração de $\mathrm{Nb}$ se deve à rejeição sofrida por este elemento durante a solidificação do Inconel 625 [12]. Esta composição química indica a presença da fase Laves como precipitado interdendrítico. É reportado que a presença de Si promove a formação da fase Laves [13] que, aliado às altas concentrações de $\mathrm{Nb}$, reforçam a possível presença desta fase. 
A Figura 9b mostra o EDS obtido no ponto 3, referente a fase matriz do revestimento. Os picos de $\mathrm{Ni}, \mathrm{Cr}$ e $\mathrm{Nb}$ obtidos são compatíveis com a composição química do Inconel 625, comprovando se tratar da matriz austenítica. Picos de Fe, presentes na região analisada, ocorrem devido à diluição deste elemento do MB para o revestimento durante a soldagem de revestimento.

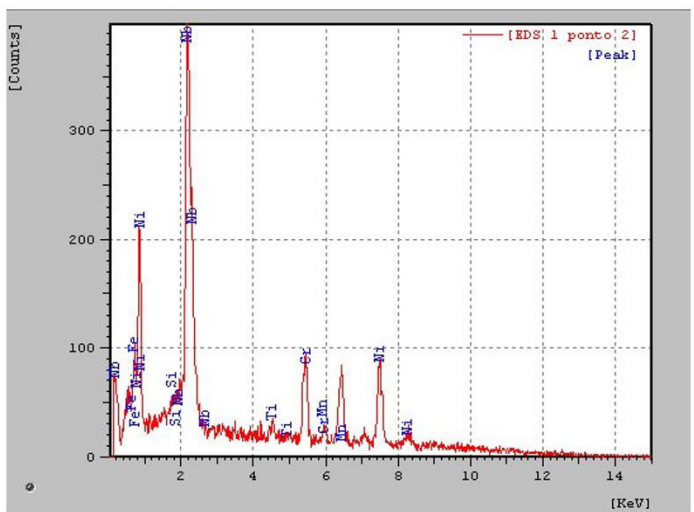

(a)

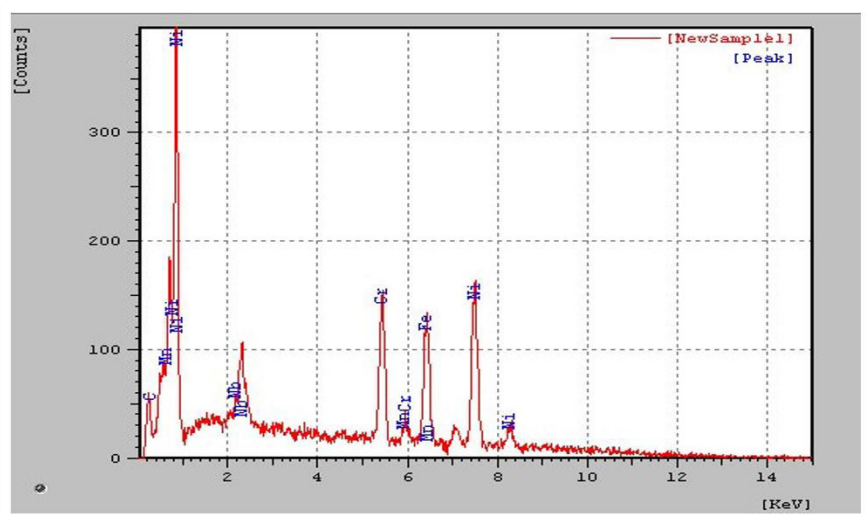

(b)

Figura 9. Análise por EDS nos pontos 1 (a) e 3 (b) indicados na Figura 8.

Os valores médios de dureza obtidos da 1a à 4a camadas foram, respectivamente, 239, 297, 285 e $320 \mathrm{HV}$. A dureza ligeiramente mais elevada obtida na última camada pode ser justificada pelo fato desta não ter sido afetada termicamente por passes posteriores de soldagem. Esses resultados estão de acordo com Ribeiro et al. [14] e Kejelin et al. [11]. Ambos reportaram que a aplicação da camada posterior de soldagem do Inconel 625 normaliza a microestrutura da camada anterior, reduzindo assim sua dureza e melhorando sua tenacidade.

Os resultados de dureza obtidos na 2a , 3a e 4a camada, na condição como soldado, estão acima dos limites recomendados pela norma NACE MR0175 [15], onde a dureza máxima especificada é de 22 HRC (250 HV) para juntas soldadas submetidas a ambientes agressivos. Esses resultados sugerem a necessidade de tratamentos térmicos posteriores para melhorar e adequar as propriedades do revestimento.

Condição Normalizado: $\left(1100^{\circ} \mathrm{C}\right.$ por $60 \mathrm{~min}$, em forno, resfriado ao ar): a Figura 10 mostra a microestrutura do MB após normalização. Pode-se observar a presença de ferrita poligonal (região clara) e de ferrita com segunda fase alinhada (região com tons claros e escuros). A microestrutura do MB normalizado é diferente da condição como soldado (comparar Figura 10 com a Figura 2). Ainda, na parte da direita da Figura 10 observa-se que, próximo à linha de fusão, houve a supressão da ZTA. A microestrutura é homogênea em todo o MB como consequência do tratamento de normalização.

O valor médio de dureza encontrado no MB, incluindo a ZTA, foi de 174 HV com valor máximo de $177 \mathrm{HV}$ e mínimo de $172 \mathrm{HV}$. Estes valores são ligeiramente superiores à condição como soldado (média de $154 \mathrm{HV}$ ). Isto se justifica pelo ciclo térmico que o MB foi submetido e à microestrutura predominantemente composta por ferrita com segunda fase alinhada obtida após normalização. Izar [16] também realizou tratamento térmico de normalização a $1100^{\circ} \mathrm{C}$ por $60 \mathrm{~min}$. em aço API $5 \mathrm{~L}$ X-52 e obteve microestrutura semelhante à aqui encontrada e dureza média de $166 \mathrm{HV}$, muito próximo aos resultados deste trabalho, de $174 \mathrm{HV}$.

A Figura 11 mostra a microestrutura obtida por MEV na interface entre o MB e o revestimento após normalização. Observa-se ao lado do metal de solda, adjacente à linha de fusão, a presença de uma zona de transição composta por uma região clara, de pequena espessura e livre de contornos de grãos, a ZPD.

A Figura 12 mostra a análise feita por EDS na ZPD, indicando um alto teor de Fe, seguido de picos médios de $\mathrm{Cr}$ e $\mathrm{Ni}$ e pequenos picos de $\mathrm{Nb}, \mathrm{Si}, \mathrm{C}$ e Mo. Esse resultado é parecido ao mostrado na Figura 6a para a condição como soldado. Por se tratar de uma região de transição, resultante da mistura incompleta de materiais, a ZPD apresenta gradientes significativos de composição química [17]. A normalização não alterou a ZPD sob o ponto de vista da microestrutura. 
Efeito dos Tratamentos Térmicos de Normalização e de Solubilização na Microestrutura de uma Junta Dissimilar Soldada entre um Tubo de Aço API 5L X-52 e o Inconel 625

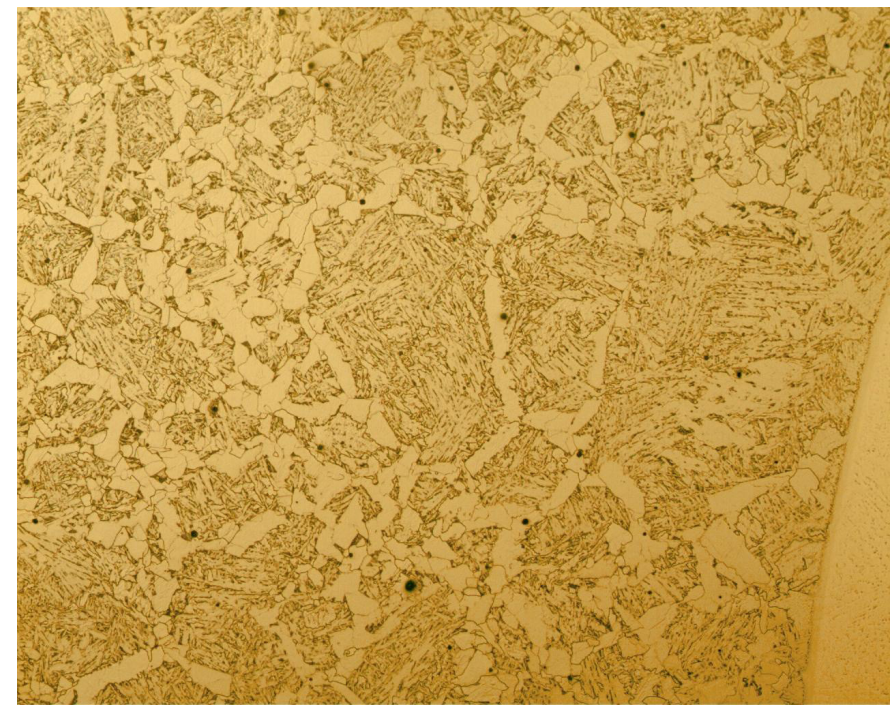

Figura 10. Microestrutura do MB normalizado a $1100^{\circ} \mathrm{C}$ por 60 min. MO: Olympus GX41. Aumento: 100X.

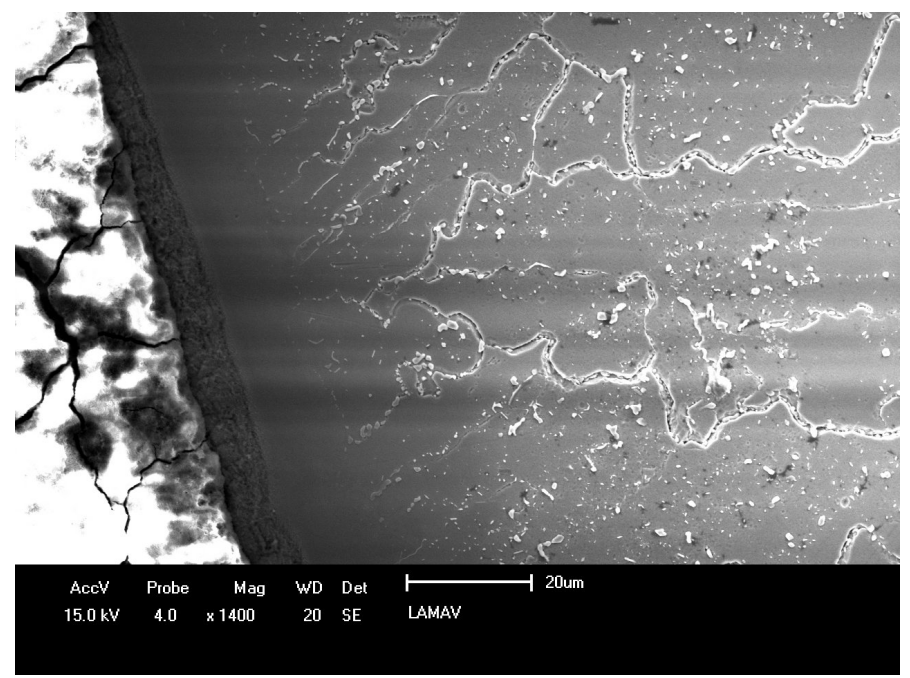

Figura 11. ZPD e microestrutura do revestimento normalizado a $1100^{\circ} \mathrm{C}$ por $60 \mathrm{~min}$. MEV. Aumento: $1400 \mathrm{X}$.

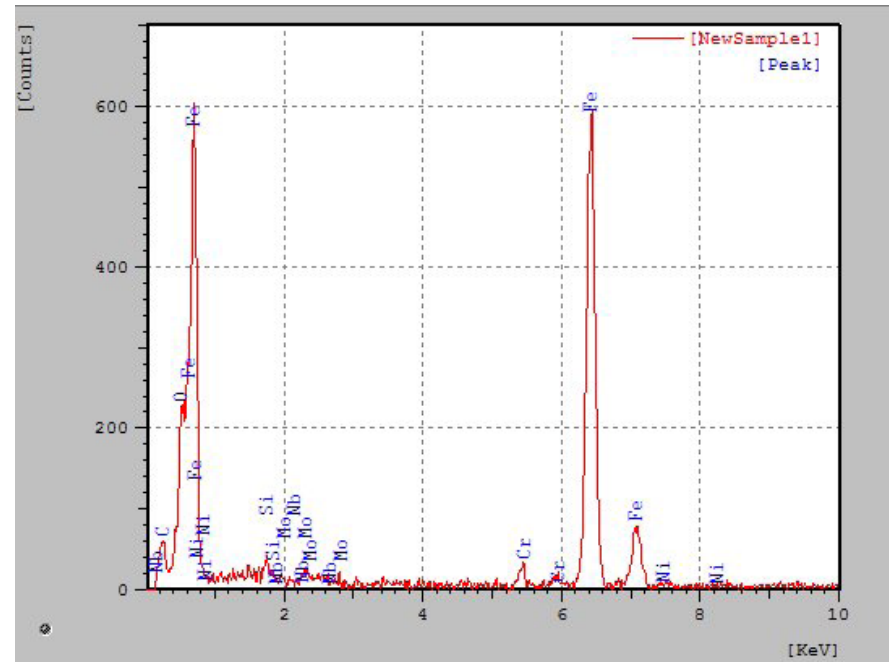

Figura 12. Análise feita por EDS na ZPD da amostra normalizada. 
A dureza obtida ao longo da ZPD após normalização teve média de 370 HV, com mínimo de 307 HV e máximo de 501 HV. Estes valores indicam a presença de martensita na ZPD. Kejelin et al. [3] relata que a dureza característica da microestrutura martensítica é acima de 340 HV. Importante salientar que a média de dureza na ZPD normalizada foi cerca de $15 \%$ inferior à obtida na ZPD na condição como soldado.

A Figura 13 mostra a microestrutura obtida no MEV em uma das camadas do revestimento após normalização. Pode ser observado que esta deixou de apresentar a morfologia dendrítica (veja Figura 7, condição como soldado) e passou a apresentar estrutura granular. Também foi observado, em todas as camadas, a precipitação de segundas fases. A Figura 14 mostra com maior aumento estes precipitados, sendo observados tanto nos contornos de grão quanto na região intergranular. Na Figura 14 são indicados três pontos, onde foi realizada análise pontual por EDS. Os pontos escolhidos representam: a matriz (1), um precipitado (2) e a região do contorno de grão (3).

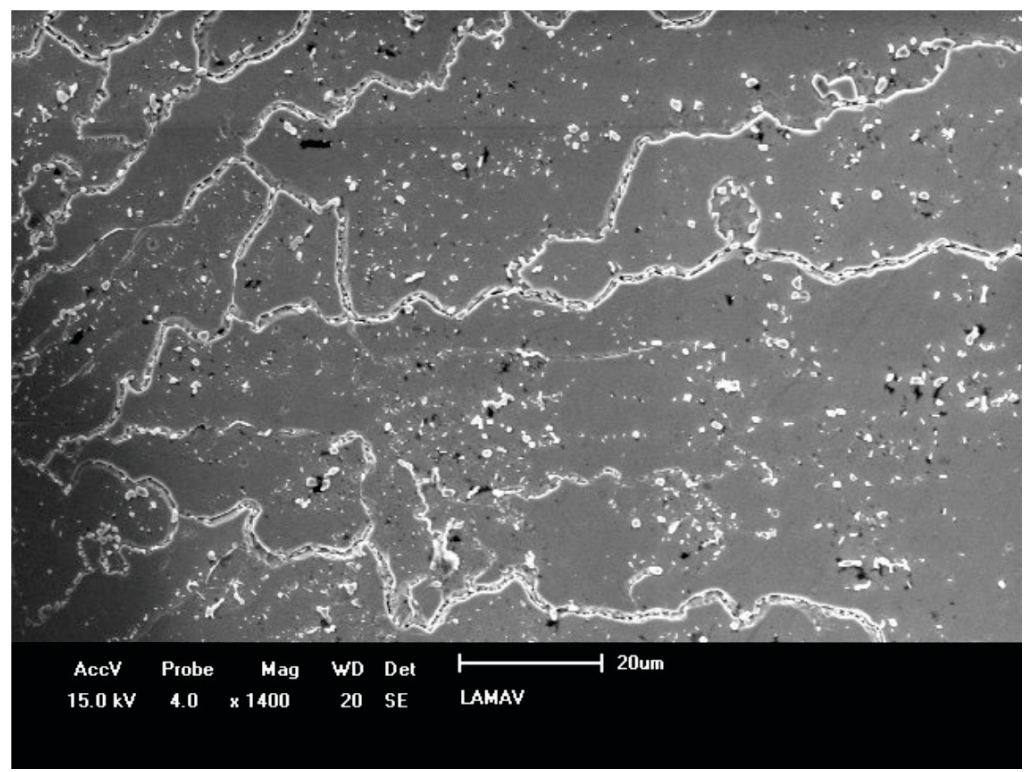

Figura 13. Precipitados formados nas camadas de revestimento após tratamento térmico de normalização. MEV. Aumento: 1400X.

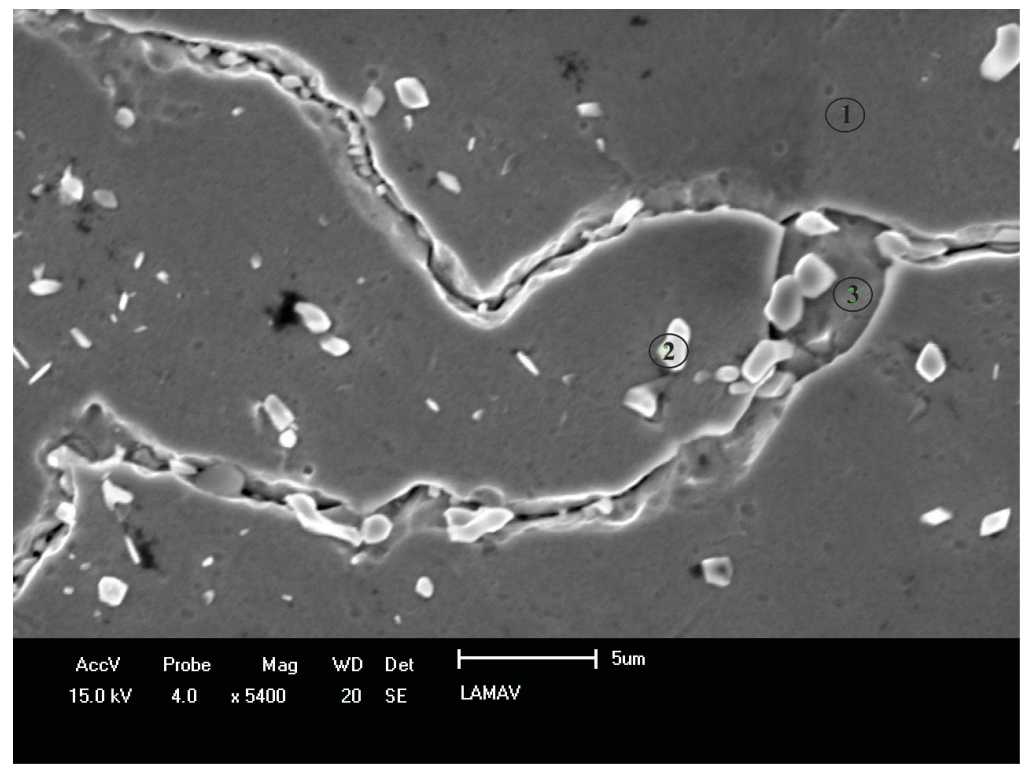

Figura 14. Precipitados formados nas camadas de revestimento após tratamento térmico de normalização e pontos de análise por EDS. MEV. Aumento: 5400X. 
Efeito dos Tratamentos Térmicos de Normalização e de Solubilização na Microestrutura de uma Junta Dissimilar Soldada entre um Tubo de Aço API 5L X-52 e o Inconel 625

Os pontos 1 e 3 , que representam a matriz e a região de contorno de grão, apresentaram resultados semelhantes aos mostrados na Figura 9b, com picos de $\mathrm{Ni}, \mathrm{Cr}$ e Mo. Os valores são parecidos à composição química do Inconel 625 apresentada na Tabela 1, evidenciando que a microestrutura do revestimento é a fase austenita. A Figura 15 mostra a análise por EDS referente ao ponto 2 da Figura 14, onde é evidenciada uma elevada concentração de Nb, $\mathrm{Ni}$ e C, que indica que os precipitados presentes nesta região são, em sua maioria, carbetos ricos em $\mathrm{Nb}$.

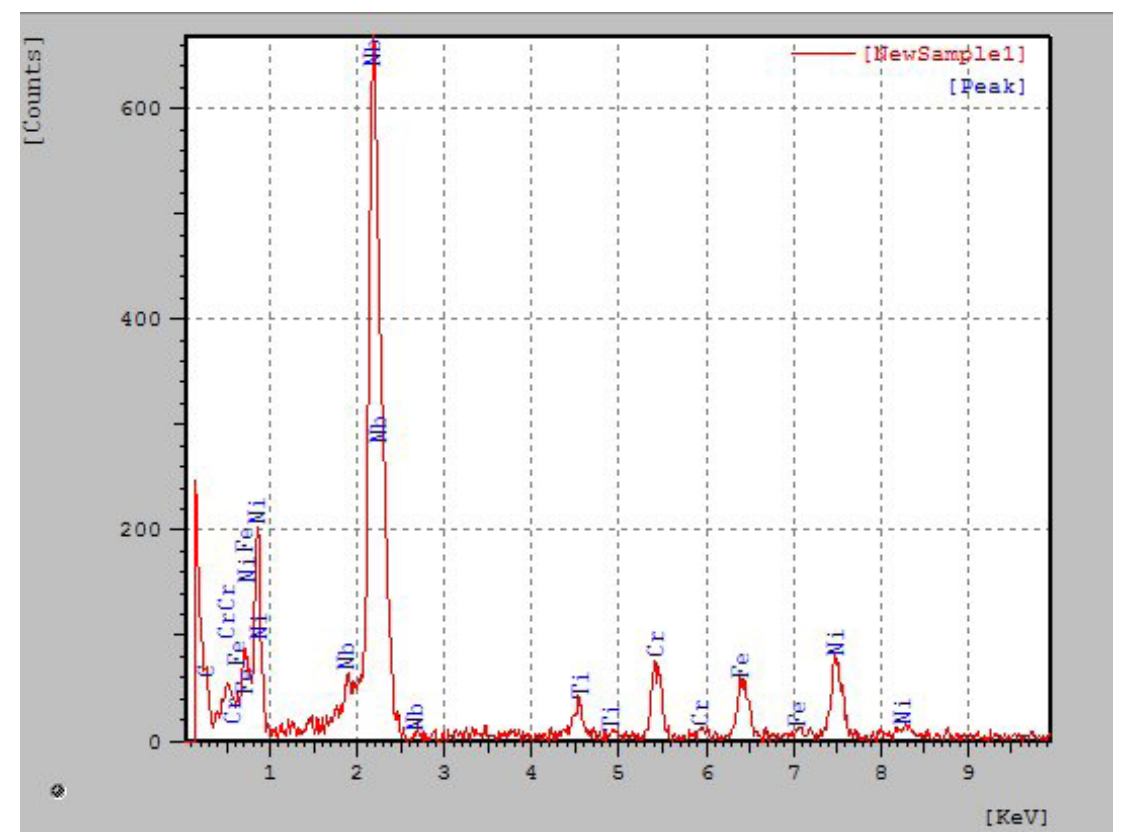

Figura 15. Análise feita por EDS no ponto 2 indicado na Figura 14.

O diagrama TTT da liga Inconel 625 mostra que os carbetos do tipo MC são estáveis a altas temperaturas, portanto é possível sua presença na microestrutura da liga após a normalização. A fase Laves, que possivelmente está presente no revestimento inconel na condição como soldado, provavelmente foi dissolvida. Shankar et al. [18] após realizar tratamento térmico a $1150{ }^{\circ} \mathrm{C}$ por $30 \mathrm{~min}$. no Inconel 625 , observou a dissolução dos precipitados presentes, exceto os carbetos de nióbio, fato também observado neste trabalho.

Em relação à dureza na condição normalizado, os valores médios obtidos da $1^{\text {a }}$ à 4 a camada foram, respectivamente, 195, 226, 211 e 206 HV. Estes valores são cerca de $26 \%$ menores que os obtidos na condição como soldado. A redução da dureza pode ser relacionada à mudança microestrutural, que deixou de ter dendrítica e passou a ser granular. A redução da dureza no revestimento após normalização está de acordo com o encontrado por Izar [16]. Importante salientar que após normalização a dureza média em todas as camadas do revestimento está de acordo com a norma NACE MR 0175 [15] e ISO 15156-3 [19], que especifica valor máximo de dureza de $250 \mathrm{HV}$ para regiões submetidas a ambientes agressivos.

Os resultados acima indicam que o tratamento de normalização foi benéfico às propriedades da junta soldada: eliminou a ZTA do metal base, reduziu a dureza da ZPD e do revestimento e aparentemente transformou a fase Laves em carbetos no revestimento de inconel 625.

Condição Solubilizado: $\left(1030^{\circ} \mathrm{C}\right.$ por 30 s, por indução, resfriado em água): A Figura 16 mostra a microestrutura do MB após solubilização, constituida de grãos de ferrita (região clara) com alguma perlita (região com tons claros e escuros). Na parte direita da Figura 16 pode ser observado que houve a supressão da ZTA, tendo ocorrido a recristalização e refino dos grãos do MB e da antiga ZTA.

A Figura 17 mostra micrografia obtida por microscopia ótica do MB (direita), o revestimento (esquerda) e a interface entre o aço e o revestimento de Inconel 625, após solubilização. A ZPD é a área central da micrografia, com tonalidade clara e sem contornos de grão. 


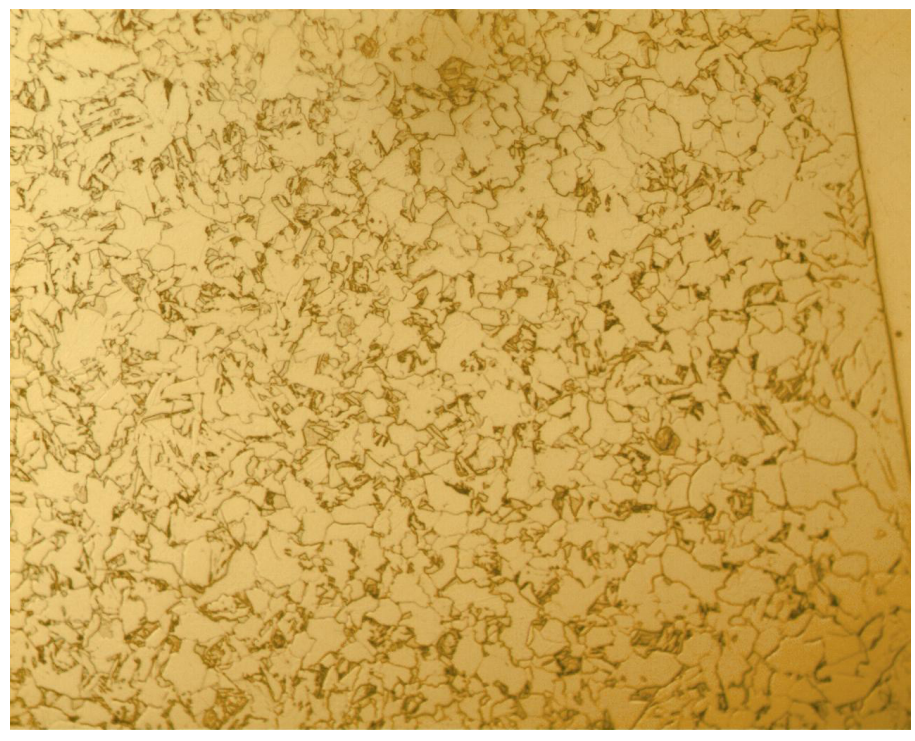

Figura 16. Microestrutura do MB solubilizado a $1030{ }^{\circ} \mathrm{C}$ por indução. MO: Olympus GX41. Aumento: $500 X$.

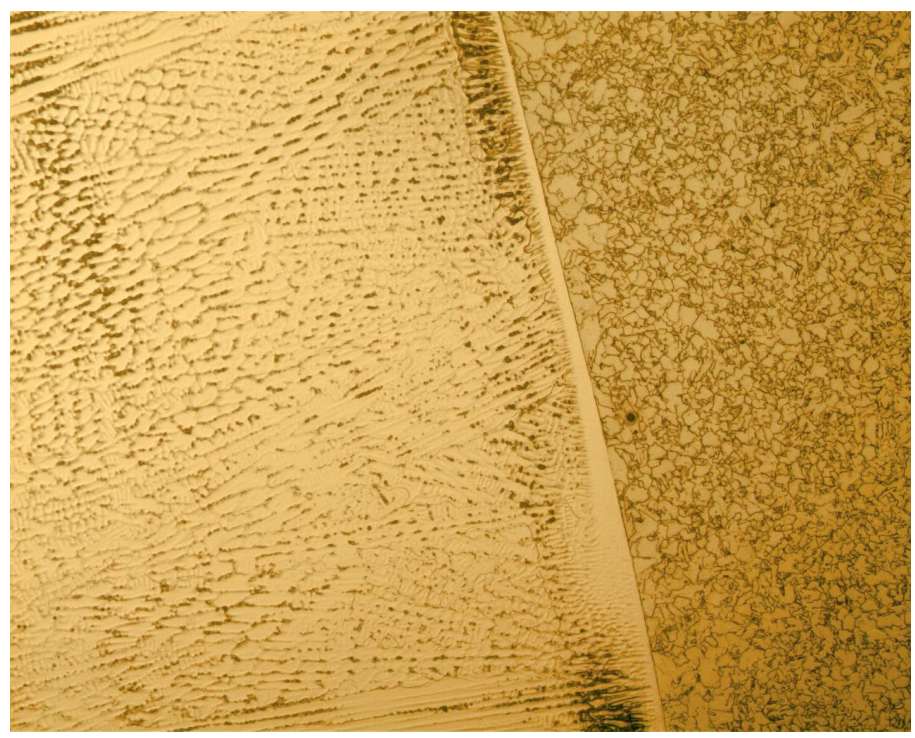

Figura 17. ZPD e microestrutura do MB e revestimento solubilizado. MO: Olympus GX41. Aumento: 200X.

O valor médio da dureza no MB e na ZTA foi de 166 HV, com mínimo de 152 HV e máximo de 174 HV. A dureza média na condição solubilizado foi $7 \%$ maior que na condição como soldado e $5 \%$ menor que na condição normalizado.

A Figura 18 mostra o MB (esquerda) a ZPD e o revestimento (direita), imagem obtida no MEV, com aumento de 1400X. No ponto 1 indicado, localizado na ZPD, foi feito análise por EDS, como mostrado na Figura 19. Observa-se que os elementos químicos identificados na região da ZPD foram Fe, Ni e Cr. Sendo que o Fe ocorre em maior quantidade que os demais elementos. O maior teor de Fe foi atribuído à diluição do MB durante a soldagem de revestimento. A composição química da ZPD após solubilização é semelhante à encontrada nas outras duas condições estudadas, como soldado (Figura 6a) e normalizado (Figura 12).

O valor médio da dureza na ZPD na condição solubilizado foi de 296 HV e demais valores entre 271 e 312 HV. Estes valores são cerca de $30 \%$ inferiores aos da ZPD do material como soldado. A redução da dureza da ZPD se deve a possível ocorrência de revenimento na microestrutura martensítica, após o aquecimento da região durante a solubilização. Doody [20] comenta que não há limites de dureza definidos com relação às ZPDs. 


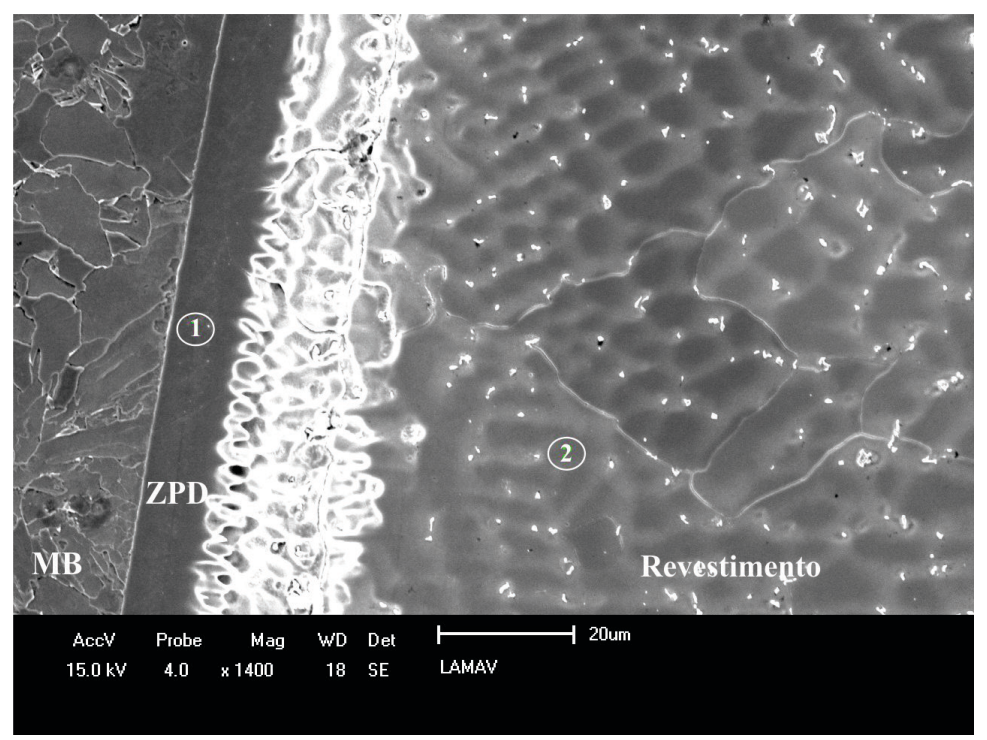

Figura 18. ZPD e microestrutura do MB (esquerda) e revestimento após solubilização. MEV e pontos de análise por EDS (ZPD - Ponto 1 e Revestimento - Ponto 2). Aumento: 1400X.

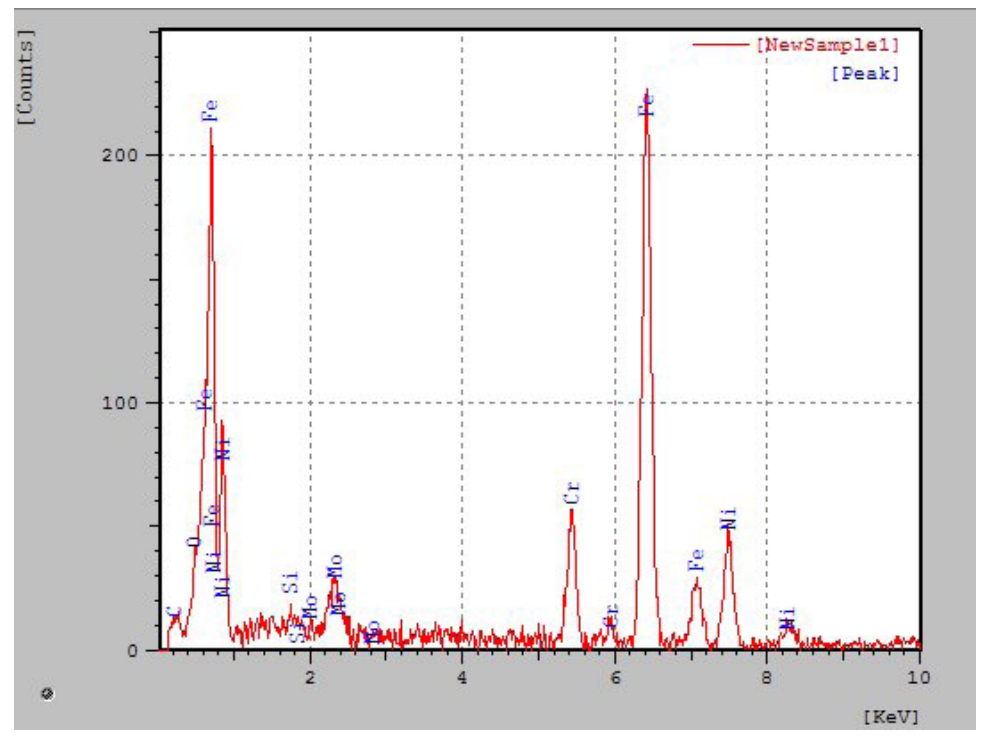

Figura 19. Análise feita por EDS na ZPD da amostra solubilizada.

As Figuras 20 e 21 mostram a microestrutura austenitica do revestimento da primeira e da quarta camada, após solubilização, onde se observa que foi mantida a morfologia dendrítica encontrada na condição como soldado (veja Figura 7), alternando entre celular, colunar e equiaxial em todas as camadas. A Figura 21 apresenta microestrutura austenitica com formato equiaxial-dendrítico, semelhante ao encontrado no trabalho de lzar [16].

A Figura 22 apresenta a microestrutura na segunda camada do revestimento de Inconel 625, sob um aumento de 4.800X, obtida no MEV. A microestrutura destacada é composta de matriz austenítica com precipitados. Nesta imagem é destacado o ponto 1 , que se encontra sobre um dos precipitados, onde foi realizada análise química por EDS, mostrado na Figura 23, onde foram identificados picos de $\mathrm{Nb}$ em grandes concentrações e a presença de $\mathrm{Ni}, \mathrm{Cr}$ e Fe em menores proporções. A fase Laves tem como fórmula química mais comuns $\mathrm{Fe}_{2} \mathrm{Ti}_{1}, \mathrm{Fe}_{2} \mathrm{Nb}$ e $\mathrm{Fe}_{2} \mathrm{Mo}$ [21]. Esta composição química, com altos teores de $\mathrm{Nb}$ e $\mathrm{Fe}$, associada à morfologia do precipitado, leva a supor que os precipitados se tratem de fase Laves, assim como os encontrados por Izar [16]. 


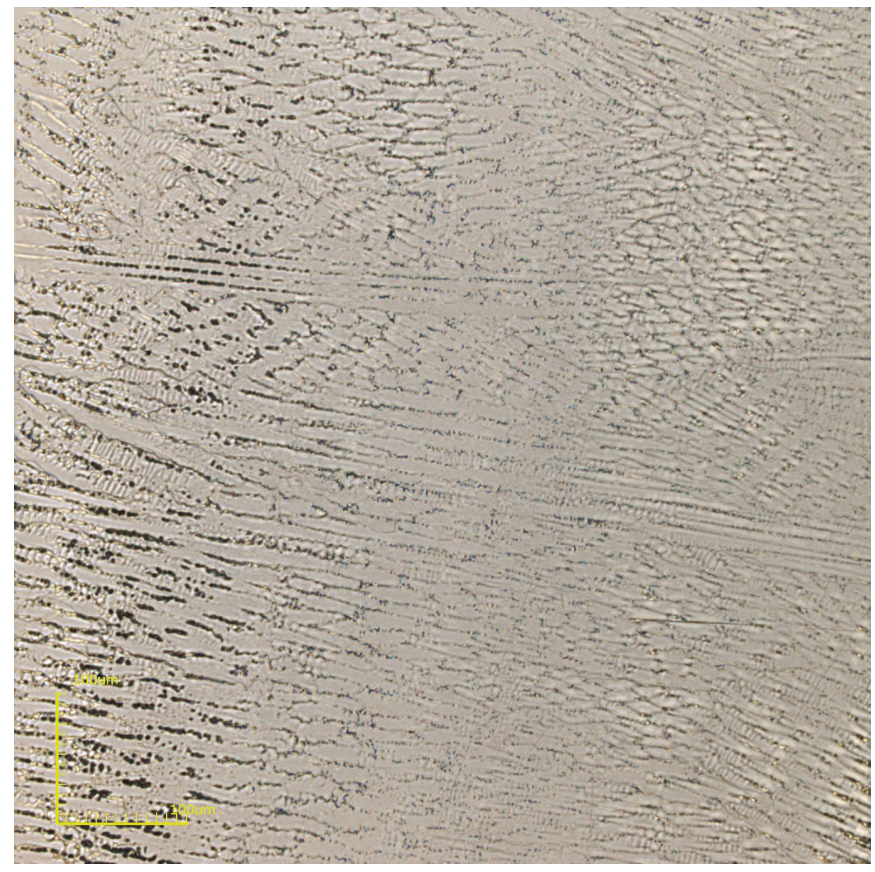

Figura 20. Microestrutura predominante da primeira camada do revestimento de Inconel 625. Microscopia Confocal.

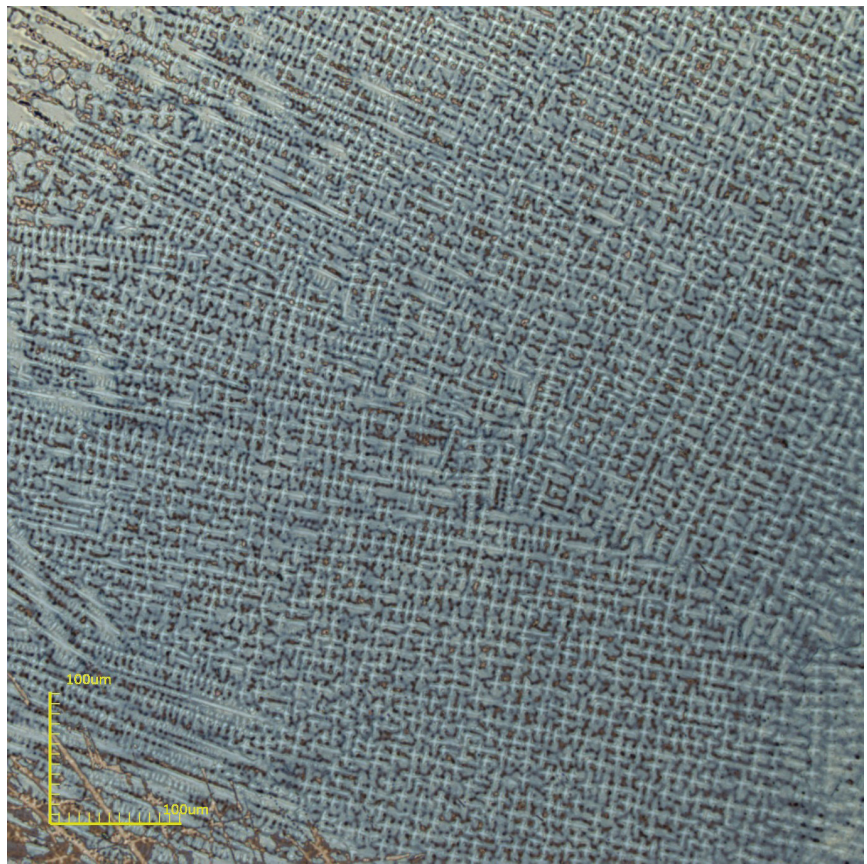

Figura 21. Microestrutura presente na quarta camada do revestimento de Inconel 625. Microscopia Confocal.

Em relação à dureza, na condição solubilizado os valores médios obtidos da 1a à 4a camada foram, respectivamente, 206, 231, 236 e 232 HV. Estes valores são cerca de $20 \%$ menores que os obtidos na condição como soldado. A redução da dureza foi suposta ter ocorrido devido ao aquecimento do revestimento durante o tratamento térmico, fenômeno observado também por Cortial et al. [22].

Já quando se compara os valores de dureza entre as camadas de revestimento após o tratamento térmico de solubilização e o de normalização, verifica-se a proximidade entre os mesmos, com diferença aproximada de $7 \%$ superior no material solubilizado. A dureza média em todas as camadas do revestimento, após a solubilização, 
Efeito dos Tratamentos Térmicos de Normalização e de Solubilização na Microestrutura de uma Junta Dissimilar Soldada entre um Tubo de Aço API 5L X-52 e o Inconel 625

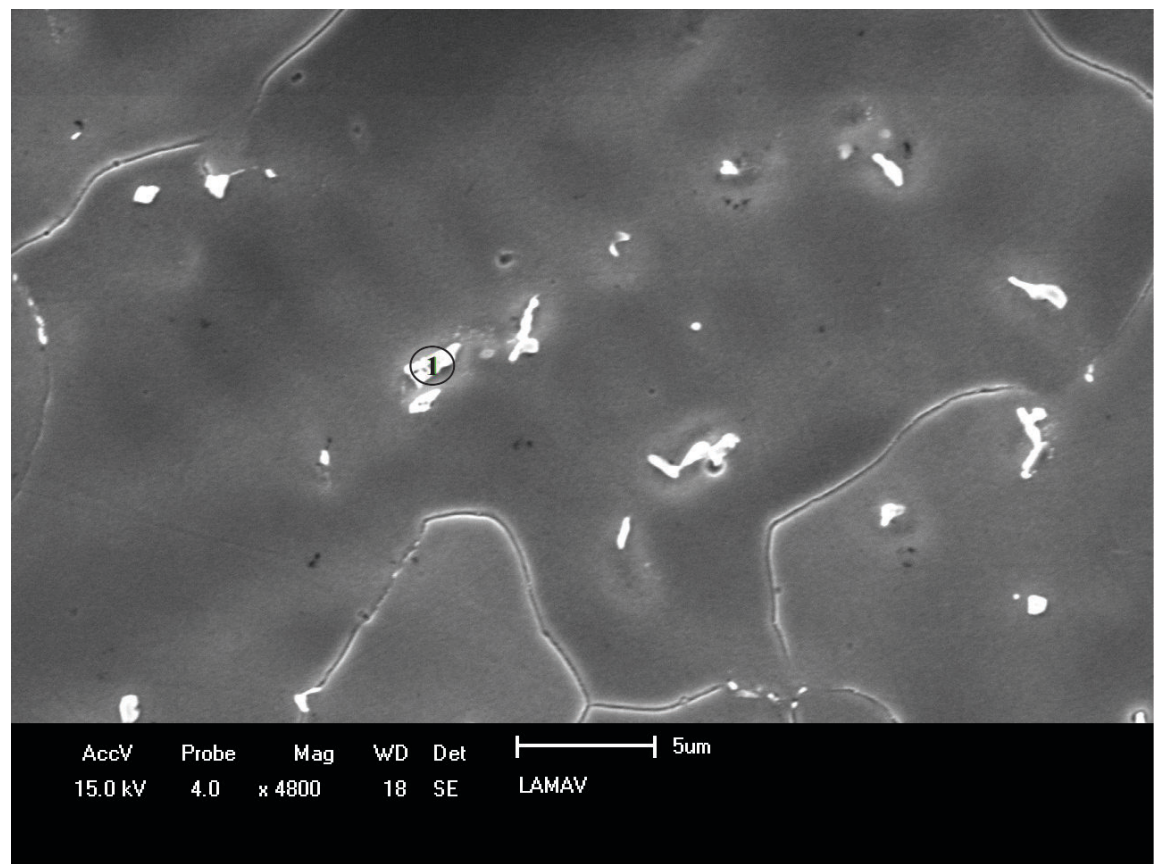

Figura 22. Precipitados presentes no revestimento após TTPS de solubilização. MEV. Aumento: 4800X.

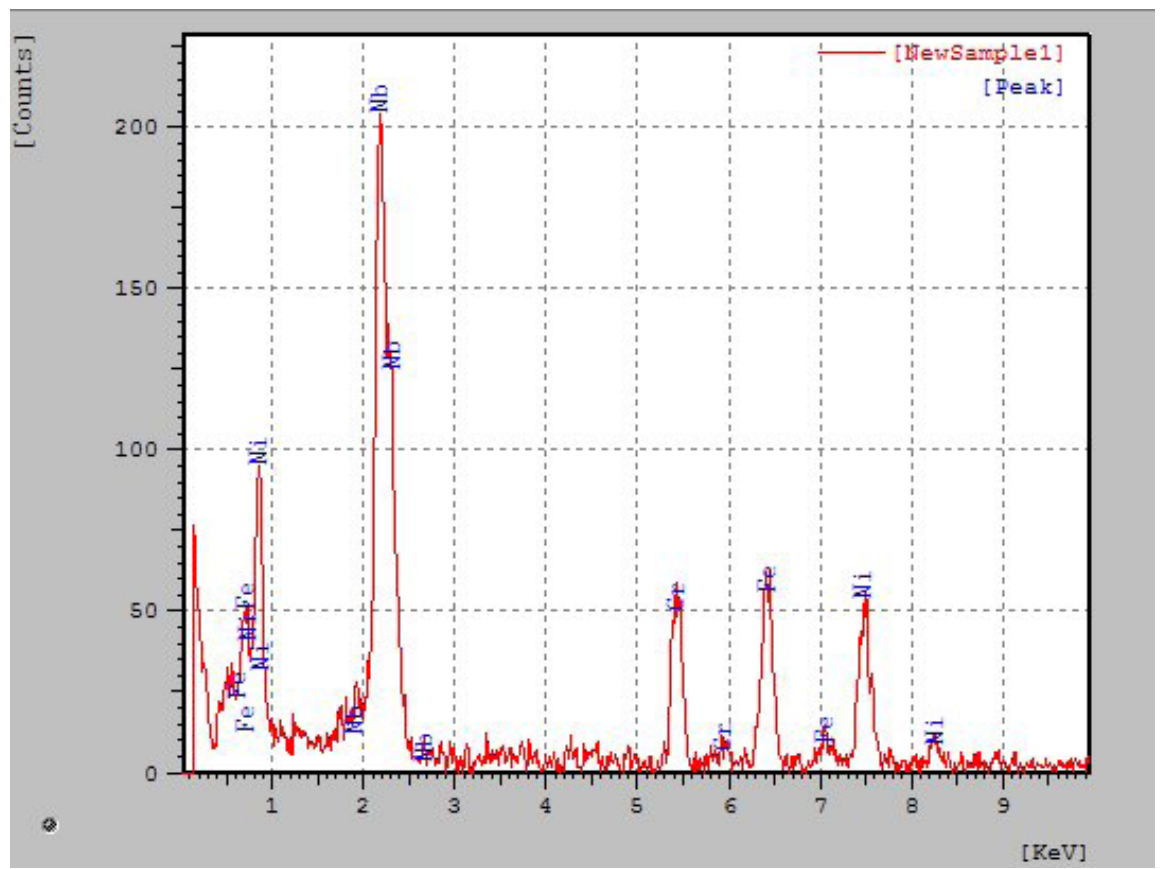

Figura 23. Análise feita por EDS no ponto 1 indicado na Figura 22, relativo a um dos precipitados do revestimento.

está de acordo com a norma NACE MR 0175 [15] e ISO 15156-3 [19], que especifica dureza máxima de 250 HV para peças submetidas a ambientes agressivos.

Os resultados acima indicam que o tratamento de solubilização foi benéfico às propriedades da junta soldada: eliminou a ZTA do metal base, reduziu a dureza da ZPD e do revestimento, porém aparentemente manteve a presença de fase Laves no revestimento de inconel 625. 


\section{Conclusões}

Com base nos resultados obtidos da avaliação metalúrgica na soldagem de revestimento do Inconel 625 sobre o aço API 5LX-65 na condição como soldado, após normalização e após solubilização, pode-se concluir que:

$\mathrm{Na}$ condição como soldado, o MB teve em sua ZTA a formação de ZGG com dureza média de 234 HV e ZGF com dureza média de 188 HV. A ZPD se apresentou clara, livre de contornos de grãos, com alto teor de ferro, com dureza média de $370 \mathrm{HV}$ e microestrutura provavelmente martensitica. O revestimento possui microestrutura austenítica com formato dendrítico celular, colunar e equiaxial com fases secundárias, que aparentam ser Laves e carbetos de $\mathrm{Nb}$. A dureza média do revestimento foi de $287 \mathrm{HV}$.

O tratamento térmico de normalização suprimiu a ZTA e promoveu um refinamento da microestrutura do MB eda ZTA, com dureza média de 174 HV. A ZPD permaneceu com sua morfologia e dimensão intactas, porém a dureza foi reduzida em cerca de $15 \%$. O revestimento após normalização apresentou estrutura granular com a possível dissolução da fase Laves e redução de sua dureza de cerca de $26 \%$ em relação à condição como soldado. A normalização foi considerada benéfica às propriedades da solda de revestimento.

O tratamento térmico de solubilização também eliminou a ZTA e refinou a microestrutura do MB e da ZTA, que apresentou dureza média de 166 HV. A ZPD manteve sua extensão e microestrutura, porém sua dureza foi reduzida em cerca de $30 \%$. O revestimento manteve sua microestrutura e precipitados, mas a dureza foi reduzida em cerca de $20 \%$. Desta forma, a solubilização também foi considerada benéfica às propriedades da solda de revestimento.

Por fim, este trabalho conclui que ambos os tratamentos térmicos foram benéficos às propriedades das tubulações de aço API $5 \mathrm{~L}$ X-52 revestidas internamente com Inconel 625. Promoveram a homogeneização da microestrutura e a redução de dureza na ZTA do MB, a redução da dureza na ZPD e, nas camadas do revestimento, a adequação da dureza às normas NACE MR0175 [15] e ISO 15156-3 [19], possibilitando assim a sua utilização em ambientes agressivos (corrosão), principalmente na indústria offshore de petróleo e gás.

\section{Referências}

[1] Costa JFM, Payão JC Fo. Resistência ao desgaste abrasivo de revestimento de ferro fundido branco alta-liga soldado pelo processo arame tubular autoprotegido. In: Anais do 3올 Seminário Brasileiro de Materiais Resistentes ao Desgaste; 1994; Fortaleza. São Carlos: UFSCar; 1994. p. 181-200.

[2] Silva CC, Afonso CRM, Ramirez AJ, Motta MF, Miranda HC, Farias JP. Aspectos metalúrgicos de revestimentos dissimilares com a superliga à base de níquel Inconel 625. Soldagem \& Inspeção. 2012;17(3):251-263. http://dx.doi.org/10.1590/ S0104-92242012000300009.

[3] Kejelin NZ, Buschinelli AJA, Bohórquez CEN. Soldagem dissimilar do aço X-60 com Inconel 625. Florianópolis: Labsolda/EMC/ UFSC; 2005.

[4] Cantarin TN. Caracterizações mecânicas e microestruturais do aço AISI 8630 modificado revestido com a liga de níquel 625 por soldagem "GTAW" [dissertação de mestrado]. São Paulo: Universidade de São Paulo; 2011.

[5] Chiaverini V. Tratamento térmico das ligas metálicas. São Paulo: ABM; 2008. 272 p.

[6] Antonio DA, Howson DDT, Rothman MF. Heat treating of superalloys. Materials Park: ASM International; 1991. (ASM Handbook; 4).

[7] Totten GE. Steel heat treatment: mettalurgy and technologies. 2nd ed. Boca Raton: Taylor \& Francis; 2006. 832 p.

[8] American Petroleum Institute. API 5L PSL-2. Specification for line pipes. USA: API; 2009. 186 p.

[9] Modenesi PJ. Soldabilidade dos aços transformáveis. Belo Horizonte: Departamento de Engenharia Metalúrgica, Universidade Federal de Minas Gerais; 2004. 100 p.
[10] Silva CC, Afonso CRM, Ramirez AJ, Motta MF, Miranda HC, Farias JP. Aspectos metalúrgicos de revestimentos dissimilares com a superliga à base de níquel Inconel 625. Soldagem e Inspeção. 2012;17(3):251-263. http://dx.doi.org/10.1590/ S0104-92242012000300009.

[11] Kejelin NZ, Buschinelli AJA, Bohórquez CEN. Soldagem dissimilar do aço X-60 com Inconel 625. Florianópolis: Labsolda/EMC/ UFSC; 2005.

[12] DuPont JN. Solidification of an alloy 625 weld overlay. Metallurgical and Materials Transactions A: Physical Metallurgy and Materials Science. 1996;27(11):3612-3620. http://dx.doi.org/10.1007/ BF02595452.

[13] Cieslak MJ, Headley TJ, Romig AD, Kollie T. A melting and solidification study of alloy 625. Metallurgical Transactions A: Physical Metallurgy and Materials Science. 1988;19(9):23192331. http://dx.doi.org/10.1007/BF02645056.

[14] Ribeiro RA, Gonçalves RB, Paranhos RPR. Caracterização de uma junta dissimilar entre aço carbono e inconel 625 obtida por soldagem por explosão. Soldagem \& Inspeção. 2017;22(1):2-13. http://dx.doi.org/10.1590/0104-9224/si2201.02.

[15] National Association of Corrosion Engineers. NACE MR0175: metals for sulfide stress cracking and stress corrosion cracking resistance in sour oilfield environments. USA: NACE; 2003. $44 \mathrm{p}$.

[16] Izar TBS. Efeito dos tratamentos térmicos pós-soldagem na microestrutura e propriedades de uma junta dissimilar entre o aço API 5L X-52 e a liga Inconel 625 [dissertação de mestrado]. Campos dos Goytacazes: Universidade Estadual do Norte Fluminense; 2015. 
Efeito dos Tratamentos Térmicos de Normalização e de Solubilização na Microestrutura de uma Junta Dissimilar Soldada entre um Tubo de Aço API 5L X-52 e o Inconel 625

[17] Omar AA. Effects of welding parameters on hard zones formation at dissimilar metal welds. Welding Journal, Miami. 1998;77(2):86-93.

[18] Shankar V, Bhanu Sankara Rao K, Mannan SL. Microestructure and mechanical properties of Inconel 625 superalloy. Journal of Nuclear Materials. 2001;288(2-3):222-232. http://dx.doi. org/10.1016/S0022-3115(00)00723-6.

[19] International Organization for Standardization. ISO 15156-3: petroleum and natural gas industries: materials for use in H2S-containing environments in oil and gas production. Part 3: cracking-resistant CRAs (corrosion-resistant alloys) and other alloys. Genebra: ISO; 2015. 85 p.
[20] Doody T. Intermediate mixed zones in dissimilar metal welds for sour service. Welding Journal. 1992;71(3):55-60.

[21] Voort VGF, Lucas GM, Manivol EP. Metallography and microstructures of heat-resistant alloys, metallography and microstructure. Materials Park: ASM International; 2004. p. 820-859. (ASM Handbook; 9).

[22] Cortial F, Corrieu JM, Vernot-Loier C.. Heat treatments of weld alloy 625: influence on the microestructure, mechanical properties and corrosion resistance. Metallurgical and Materials Transactions A: Physical Metallurgy and Materials Science. 1995;26(5):1273-1286. http://dx.doi.org/10.1007/BF02670621. 